\title{
Circadian Rhythm Hypotheses of Mixed Features, Antidepressant Treatment Resistance, and Manic Switching in Bipolar Disorder
}

\author{
Heon-Jeong Lee ${ }^{1}$, Gi-Hoon Son ${ }^{2}$ and Dongho Geum ${ }^{3}$ \\ ${ }^{1}$ Department of Psychiatry, Korea University College of Medicine, Seoul, Republic of Korea \\ ${ }^{2}$ Department of Legal Medicine, Korea University College of Medicine, Seoul, Republic of Korea \\ ${ }^{3}$ Graduate School of Medicine, Korea University, Seoul, Republic of Korea
}

\begin{abstract}
Numerous hypotheses have been put forth over the years to explain the development of bipolar disorder. Of these, circadian rhythm hypotheses have gained much importance of late. While the hypothalamus-pituitary-adrenal (HPA) axis hyperactivation hypothesis and the monoamine hypothesis somewhat explain the pathogenic mechanism of depression, they do not provide an explanation for the development of mania/hypomania. Interestingly, all patients with bipolar disorder display significant disruption of circadian rhythms and sleep/wake cycles throughout their mood cycles. Indeed, mice carrying the Clock gene mutation exhibit an overall behavioral profile that is similar to human mania, including hyperactivity, decreased sleep, lowered depression-like behavior, and lower anxiety. It was recently reported that monoamine signaling is in fact regulated by the circadian system. Thus, circadian rhythm instability, imposed on the dysregulation of HPA axis and monoamine system, may in turn increase individual susceptibility for switching from depression to mania/hypomania. In addition to addressing the pathophysiologic mechanism underlying the manic switch, circadian rhythm hypotheses can explain other bipolar disorder-related phenomena such as treatment resistant depression and mixed features.
\end{abstract}

Psychiatry Investig 2013;10:225-232

Key Words Bipolar disorder, Circadian dysregulation.

\section{INTRODUCTION}

Mood disorders are a major cause of morbidity worldwide and a potentially life-threatening condition because of the risk of suicide. ${ }^{1,2}$ In response to overwhelming stressful life events, depressive mood may be considered a somewhat normal phenomenon. However, it turns problematic when mood episodes are induced by minor stressors, when episodes without apparent stressors become recurrent, and when individuals suffer a serious manic episode. Two groups of mood disorders are broadly recognized: major depressive disorder (MDD) and bipolar disorder (BD). MDD is also known as unipolar depression to distinguish it from $\mathrm{BD}$. The reported prevalence rate of MDD is $5-16 \%$ and that of $\mathrm{BD}$ is approximately $5-6.4 \%$ in the general population. ${ }^{3,4}$ A combination of genetic, envi-

Received: August 5, 2013 Revised: August 6, 2013

Accepted: August 6, 2013 Available online: September 16, 2013

$\triangle$ Correspondence: Heon-Jeong Lee, MD, PhD

Department of Psychiatry, Anam Hospital, Korea University College of Medicine, 73 Inchon-ro, Seongbuk-gu, Seoul 136-705, Republic of Korea Tel: +82-2-920-6721, Fax: +82-2-929-7679, E-mail: leehjeong@korea.ac.kr

(a) This is an Open Access article distributed under the terms of the Creative Commons Attribution Non-Commercial License (http://creativecommons.org/licenses/by$\mathrm{nc} / 3.0$ ) which permits unrestricted non-commercial use, distribution, and reproduction in any medium, provided the original work is properly cited. ronmental, and social factors is believed to be involved in the development of mood disorders; ${ }^{5-7}$ however, the underlying pathomechanism, particularly with regard to $\mathrm{BD}$, remains unclear.

The circadian system regulates daily rhythms of physiology and behavior, such as the sleep/wake cycle, body temperature, hormonal secretion, and mood. ${ }^{8}$ Interestingly, one of the most prominent clinical characteristics of $\mathrm{BD}$ is its rhythmicity. ${ }^{9} \mathrm{In}$ deed, several clinical reports have described phase advances or fast circadian rhythms in BD. For example, Kripke et al. ${ }^{10}$ reported that 5 out of 7 patients with BD exhibited fast circadian rhythms, which were slowed by the representative mood stabilizer, lithium. Furthermore, it has been reported that lithium can slow down circadian periodicity and modify circadian cycle length across species. ${ }^{11}$ In one study, compared to healthy controls, manic patients demonstrated higher nocturnal cortisol levels and an earlier timing of the nadir of the circadian rhythm. ${ }^{12}$

A considerable subset of patients with MDD or BD improve rapidly and definitely after sleep deprivation therapy. ${ }^{13}$ The social zeitgeber theory suggests that stressful life events lead to the disruption of "social zeitgebers" such as sleep sche- 
dule and mealtime, which in turn alter molecular and cellular rhythms in susceptible individuals, ultimately resulting in mood disorders. ${ }^{14}$ Social rhythm stabilization by interpersonal and social rhythm therapy is effective at reducing relapse in BD. ${ }^{15}$ Furthermore, bright light therapy is purportedly effective for treating seasonal and non-seasonal major depression as well as bipolar depression. ${ }^{16,17}$ Such clinical findings support the hypothesis that circadian rhythm dysfunction plays a causal role in mood disorders.

Recently, an excellent review by McClung ${ }^{18}$ summarized the latest data that implicate the circadian system as a vital regulator of a variety of systems believed to play a role in the development of mood disorders. Moreover, McCarthy and Welsh ${ }^{19}$ reported that circadian clock dysfunction can cause mood disorders; they suggested that non-suprachiasmatic nucleus circadian clocks such as those located in the lateral habenula, ventral tegmentum, and hippocampus could directly contribute to the pathophysiology of mood disorders.

When treating patients with $\mathrm{BD}$, clinicians often encounter challenges that cannot be readily explained. For example, some patients with $\mathrm{BD}$ demonstrate poor response to antidepressant treatment, whereas others abruptly switch to mania or become rapid cyclers when treated with antidepressants. Such phenomena can even be observed in the same subject using the same antidepressant at different time points. A mixed state, whereby symptoms of mania and depression occur simultaneously, is another problematic occurrence. While the coexistence or rapid alternation of depressive and manic symptoms in the same episode may indicate a more severe form of $\mathrm{BD}$, the definition of a mixed state is not well established and its mechanism is not well understood. We suggest that circadian rhythm hypotheses may explain the mechanism of mixed features, treatment resistant depression, and manic switching in mood disorders.

\section{HYPOTHESES}

While many hypotheses exist regarding the pathogenesis of mood disorders, we believe 3 major vulnerability factors must be considered while rating their pertinence. These include hypothalamus-pituitary-adrenal (HPA) axis hyperactivation, monoamine dysregulation, and circadian rhythm dysregulation. These 3 vulnerability factors can potentially affect each other; therefore, we put forward the triple susceptibility model of BD (Figure 1).

Previous studies have reported that stress during early life can cause alterations in HPA axis functioning later in life..$^{20,21}$ Findings from animal studies suggest that early-life stress can produce persistent epigenetic changes that lead to hyperactivity of the HPA axis in adulthood, which in turn increases sus-

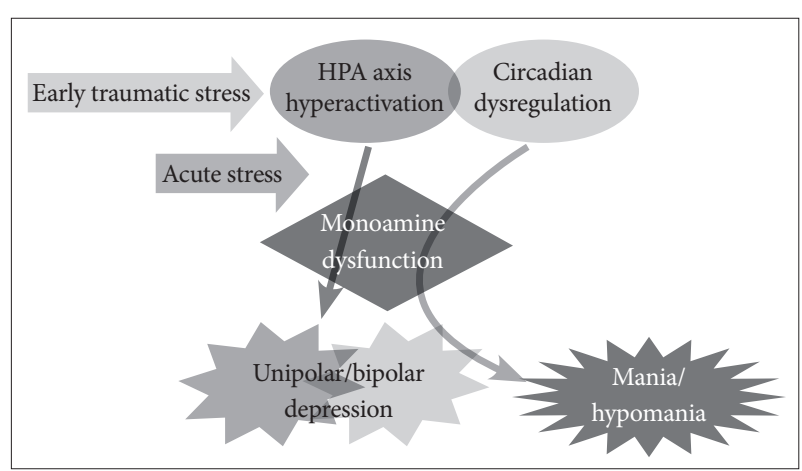

Figure 1. Triple susceptibility model of bipolar disorders. In addition to HPA axis hyperactivation and monoamine dysfunction, circadian rhythm dysregulation induces mania/hypomania via monoamine overactivity.

ceptibility to mood disorders. ${ }^{22,23}$ Interestingly, HPA axis hyperactivity in depression has been associated with hypercortisolemia and reduced inhibitory feedback. Studies have consistently demonstrated that glucocorticoid receptor (GR) function is impaired in MDD, resulting in reduced GR-mediated negative feedback on the HPA axis. ${ }^{24,25}$ Patients with mood disorders also demonstrate reduced GR mRNA levels in the hippocampus and frontal cortex..$^{26,27}$ The crucial role of GR signaling in HPA axis regulation was confirmed in animal models of specific glucocorticoid receptor (NR3C1) knockouts. ${ }^{28}$ Compared to wild type mice, $\mathrm{Nr} 3 \mathrm{c} 1$ gene knockdown mice exhibit increased stress-induced corticosteroid levels and impaired negative feedback with increased helplessness after stress. ${ }^{29}$ Furthermore, human genetic studies have reported that polymorphisms in GR genes are associated with mood disorders, especially BD. ${ }^{30-32}$

Monoamine dysregulation is another major hypothesis of mood disorders. Researchers have proposed that depression is caused by a functional deficiency of brain monoaminergic neurotransmitters such as norepinephrine, serotonin, and/or dopamine, whereas mania is caused by functional excess of monoamines at critical synapses in the brain. ${ }^{33-35}$ This hypothesis is based on the correlation of psychiatric symptoms and cellular actions of a variety of psychotropic agents. In the 1950s, monoamine oxidase inhibitors and tricyclic antidepressants were accidentally identified to be effective treatments for depression. Although the monoamine hypothesis received some criticism, ${ }^{36}$ it has been the major focus of pathophysiological and pharmacotherapy research for mood disorders. Individuals with an underlying vulnerability of HPA overactivity are susceptible to stress and are easily depressed following impairment of hippocampal monoaminergic neurotransmission. ${ }^{37,38}$ According to the first 2 hypotheses, individuals with a preexisting vulnerability with regard to the HPA axis and the monoamine system may be easily depressed in response to a stressful life event. 
Some individuals under depression demonstrate symptoms of mania or hypomania in these situations, although this phenomenon is not clearly understood. Traditional psychoanalysts have regarded the occurrence of these symptoms as "manic defenses" wherein the patient uses it to avoid the depression after being convicted for destroying an internal object. ${ }^{39}$ We suggest that some individuals under depression switch to mania/hypomania caused by circadian rhythm instability in addition to susceptibility to HPA axis hyperactivity and monoamine system dysfunction (Figure 1).

\section{WHAT IS CIRCADIAN SYSTEM?}

Circadian rhythms are cyclic and persistent patterns of behavior, physiological changes, and mental characteristics exhibited by most living organisms on the Earth, from bacteria to humans. They occur with a 24 -h period and are thus roughly reflective of the time it takes for the Earth to complete a rotation. Generally, it is believed that circadian clocks evolved in parallel with the geological history of the Earth, and that they have since been fine-tuned under selection pressures imposed by cyclic environmental changes. ${ }^{40}$ The rhythm is endogenous in humans and other organisms. ${ }^{41}$ In the absence of external time cues, it often persists for a slightly longer period than 24 $\mathrm{h}$; however, in normal conditions, it is synchronized to a $24-\mathrm{h}$ light/dark cycle. In humans and other mammals, light stimuli falling on the retina excite intrinsically photosensitive retinal ganglion cells, which send their axons to the suprachiasmatic nuclei (SCN). The SCN, located in the anterior hypothalamus above the optic chiasm, is considered the master pacemaker of circadian rhythms in mammals. ${ }^{42}$ Indeed, lesions of the SCN disrupt circadian oscillations lead to arrhythmicity in animals. Circadian rhythmicity can be restored by implanting fetal SCN cells into the arrhythmic host. ${ }^{43,44}$ The SCN orchestrates circadian rhythms in behavior and physiology via endocrine and neural pathways. Projections from the SCN to other hypothalamic nuclei and other brain regions control various rhythms such as sleep-wake cycles, body temperatures, and hormonal levels. ${ }^{45,46}$ Individual cells in the SCN, functioning as individual circadian oscillators, can independently regulate their own rhythm and can couple to form a master pacemaker. ${ }^{47}$ As demonstrated recently, hormonal systems that are under distinct circadian control include melatonin and the HPA axis including cortisol, the hypothalamicpituitary-thyroid axis, and epinephrine. ${ }^{48,49}$ In addition, hormones under SCN control may serve to entrain circadian oscillations in peripheral tissues. ${ }^{50}$

\section{WHAT HAPPENS TO THE CIRCADIAN SYSTEM IN BIPOLAR DISORDER?}

Circadian system instability is observed in BD; virtually all patients possess major alterations in circadian functions such as sleep, activity, hormonal secretions, and appetite..$^{51}$ Findings from various studies have revealed that patients with $\mathrm{BD}$ demonstrate seasonal patterns of behavior, with more manic episodes observed during the spring and summer months. ${ }^{52,53}$ This highlights a potential circadian component of the pathophysiology of $\mathrm{BD}$, which is possibly influenced by alterations in the photoperiod, i.e., seasonal changes in day length. Normalization of both sleep and wake cycles and social zeitgebers are often essential for clinical recovery, whereas disruption to circadian rhythms could trigger manic episodes. ${ }^{54}$ Prevalence of mania is higher in subjects with delayed sleep phase syndrome than in controls. ${ }^{55}$ This is consistent with reports stating that compared to controls, patients with $\mathrm{BD}$ have a greater evening preference..$^{56}$ Recently, an association between circadian gene variants and $\mathrm{BD}$ has been described, ${ }^{57-63}$ which may suggest that the internal regulation of circadian rhythms in $\mathrm{BD}$ is weak and susceptible to both internal and external influences. In contrast, genome-wide association studies (GWAS) have not identified BD-associated clock genes; ${ }^{64-66}$ however, contrasting finding was obtained upon reanalysis of 14 GWAS studies using a more focused approach. This study revealed that associations between $\mathrm{BD}$-spectrum illnesses and lithium-responsiveness were enriched among core clock genes and pervasively rhythmic clock-controlled genes ${ }^{67}$ Moreover, combining GWAS findings with the findings of convergent functional genomic studies also implicates several clock genes in $\mathrm{BD}^{68}$

Several other experiments have indicated a link between disrupted circadian rhythms and manic behavior in mammals. For example, findings from a study that used mice carrying a mutation in the circadian gene, Clock, indicated that Clock gene mutations increase the exploratory behavior and activity of mice when exposed to a novel and stressful environment. ${ }^{69}$ Furthermore, in a forced swim test, where learned helplessness can be analogous to depression, Clock mutant mice spent significantly more time swimming in the forced swim test than wild-type mice did. ${ }^{69}$ Glycogen synthase kinase- $3 \beta$ has recently been implicated as a central regulator of the circadian clock, ${ }^{70}$ and this enzyme is a known target of the representative mood stabilizer lithium..$^{71}$ Lithium modulates circadian rhythms by lengthening the circadian period in several organisms, including Drosophila, rodents, and humans; an effect that may be important for its therapeutic purposes. ${ }^{1011,72-76}$ Additionally, another mood stabilizer, valproate, alters the expression of several circadian genes in the amygda- 
la, ${ }^{77}$ whereas chronic treatment with the antidepressant, fluoxetine, increases the expression of Clock and Bmal1 in the hippocampus. $^{78}$

Regarding the effects of light exposure, patients with BD appear to be more sensitive to the biological effects of light. ${ }^{79}$ The antidepressant effects of bright light therapy and sleep deprivation are more effective in these patients than in patients with unipolar depression. ${ }^{80,81}$ Bright light therapy precipitates hypomanic/manic episodes in susceptible patients, ${ }^{82-84}$ and dark therapy is effective in manic patients. ${ }^{85}$ Most successful treatments for mood disorders rely on altering the circadian cycle. ${ }^{86}$ Altogether, these findings support the view that circadian regulatory processes in the brain are important for the development and treatment of mood disorders, in particular for manic episodes.

\section{CIRCADIAN SYSTEM AND MONOAMINE SIGNALING}

Numerous studies have reported that monoamines such as serotonin, norepinephrine, and dopamine exhibit circadian rhythmicity in their levels, release, receptors, and synthesisrelated enzymes. ${ }^{18}$ Recently, animal studies have suggested that there may be a link between circadian-clock components and regulation of the monoamine system. ${ }^{87}$ For example, it was observed that transcription of the monoamine oxidase $\mathrm{A}$ (MAOA) promoter is regulated by the clock components, Bmal1, Npas2, and Per2 in mice, and a mutation in Per 2 in mice leads to reduced expression and activity of MAOA in the mesolimbic dopaminergic system. Increased levels of dopamine and altered neuronal activity in the striatum were also noted, which might have led to mania-like behavioral alterations in Per 2 mutant mice. ${ }^{88}$ Spencer et al. ${ }^{89}$ reported that mPer 1 and mPer 2 messenger RNA levels are altered in the nucleus accumbens in response to chronic stress in mice. They also reported that selective knockdown of both mPer 1 and $m P e r 2$ via RNA interference in this region induces anxiety-like behavior.

Dominant-negative mutant (Clock $\Delta 19)$ mice have a behavioral profile that is very similar to manic symptoms such as hyperactivity, low anxiety/depression behavior, and increased reward seeking. ${ }^{90,91}$ Interestingly, Clock $\Delta 19$ mice have increased dopamine synthesis and activity as well as increased tyrosine hydroxylase expression in the ventral tegmental area (VTA).$^{90,92}$ Furthermore, it was observed that the majority of mania-like behavior in these mice was reversed with chronic lithium treatment. ${ }^{91}$ Lithium also restored normal levels of VTA dopaminergic activity in the Clock mutants. ${ }^{92}$

The circadian system regulates monoaminergic activity in various brain regions that control mood and behavior through local expression of clock genes as well as indirect connections originating in the SCN. The SCN projects monosynaptically to multiple hypothalamic nuclei, which subsequently communicate with regions that synthesize dopamine, serotonin, and norepinephrine. ${ }^{18}$

\section{ANTIDEPRESSANT-RESISTANT DEPRESSION AND MANIC SWITCHING}

A considerable number of patients diagnosed with unipolar depression are later diagnosed with BD. A survey reported that $48 \%$ of patients with $\mathrm{BD}$ consult 3 physicians before they are correctly diagnosed, while $38 \%$ of the patients take more than 10 years for a correct $\mathrm{BD}$ diagnosis. ${ }^{93}$ Early and precise diagnosis of $\mathrm{BD}$ and early effective treatment intervention are pivotal considering the evidence that antidepressants sometimes, if not always, stimulate poor treatment response and manic switching or rapid cycling in patients with $\mathrm{BD}$ in depressive episodes. ${ }^{94}$

Previous studies have suggested that monoaminergic antidepressants might increase the risk of manic switching ${ }^{55,96}$ or rapid cycling. ${ }^{97-99} \mathrm{~A}$ strong association between poor antidepressant response and a subsequent change in diagnosis to $\mathrm{BD}$ has also been reported. ${ }^{100}$ In a controlled trial, antidepressant-induced manic switching was observed in up to $50 \%$ of subjects not treated with mood-stabilizing medication. ${ }^{101}$ However, despite these findings, the mechanism underlying manic switching and antidepressant resistance remains elusive. Interestingly, decreased amount of total sleep and shortened latency of rapid eye movement sleep occur at the time of the switch to mania, ${ }^{102,103}$ and disturbed sleep patterns are also associated with circadian fluctuations in body temperature and hormone secretion as well as catecholamine increase. ${ }^{9}$ Some treatment methods for depression have a phase-advancing effect on circadian rhythms. Morning light therapy leads to a phase advance in biological rhythms in seasonal affective disorder, and phase alignment either through light therapy or melatonin treatment is necessary for recovery. ${ }^{104}$ Antidepressants such as fluoxetine produce a phase advance in the firing of SCN neurons in rats. ${ }^{105}$ These findings implicate changes in sleep patterns and other circadian disturbances in the switch process.

We hypothesize that manic switching and treatment resistance to antidepressants in $\mathrm{BD}$ can be explained by circadian rhythm hypotheses. A percentage of patients with recurrent depression may also possess a covert form of BD. Switching may relate to the circadian rhythmic phase, wherein individuals experience depression upon phase delay and slowingdown of the circadian rhythm, whereas they come out of the depressive state upon quickening up of the circadian rhythm 
and phase advancement. Even though patients with depression act as if they are in the same depressive state, they may have different varieties of circadian phase disorders. This is depicted in Figure 2. Furthermore, when the patient's mood is on the downhill slope leading to depression during the slower circadian phase, they do not respond to antidepressant treatment; however, when the mood is on the uphill slope towards euthymic or elated mood and the circadian rhythm is faster, patients are more responsive and manic switching can be rendered.

\section{HOW CAN MIXED STATES BE EXPLAINED?}

Mixed state, also known as dysphoric mania, agitated depression, mixed features, or a mixed episode, is a condition during which features of mania and depression occur simultaneously. However, the definition and pathophysiology of mixed states are not well established. Occasionally, the mood alternation can take place over the course of a day or more, but in other instances, alternations between depressed and manic manifestations may occur over a few hours or even switch ba$\mathrm{ck}$ and forth within a few minutes.

Kraepelin ${ }^{106}$ suggested that some mixed states are transitions between depressive and manic episodes. Transitions between manic or depressive states are common, as previously demonstrated in a longitudinal study. ${ }^{107}$ Polyphasic episodes, in which state changes occur without a euthymic mood period, resemble mixed states. ${ }^{108}$ Interestingly, Sit et al. ${ }^{17}$ reported that mixed states were induced by morning light treatment in women with bipolar depression; however, midday light therapy did not induce mixed states. This finding suggests that abrupt phase advancement by morning light therapy underlies the pathomechanism of mixed states.

Recently, in an animal study, Mukherjee et al. ${ }^{109}$ reported that Clock knockdown, specifically in the VTA, results in hyperactivity and a reduction in anxiety-related behavior, which is phenotypically similar to Clock mutant mice. However, in their study, VTA specific knockdown also resulted in a substantial increase in depression-like behavior, creating an overall mixed state. They further reported that Clock knockdown in the VTA also altered the circadian period and amplitude, suggesting a role for VTA Clock gene in the regulation of circadian rhythms.

We suggest that circadian rhythm hypotheses may explain the pathophysiology of mixed states. Therefore, for example, if a patient with BD has a serious course of illness and if his mood shifting occurs without a substantial period of mood stability, the transitional period between slow and fast circadian phases may result in unstable mood leading to a mixed state of depressive and manic symptom at the same time (Figure 3). The rapid transitional period of biological rhythm does not persist for long time because of the existing sustained endogenous circadian rhythm. For example, we expe-
Figure 2. When the mood state is on the downhill slope in the slower circadian phase leading to depression, antidepressants is not effective. In contrast, when the mood on the uphill slope is faster circadian rhythm leading to euthymia or mania, antidepressants can induce very fast response or sometime render manic switch.
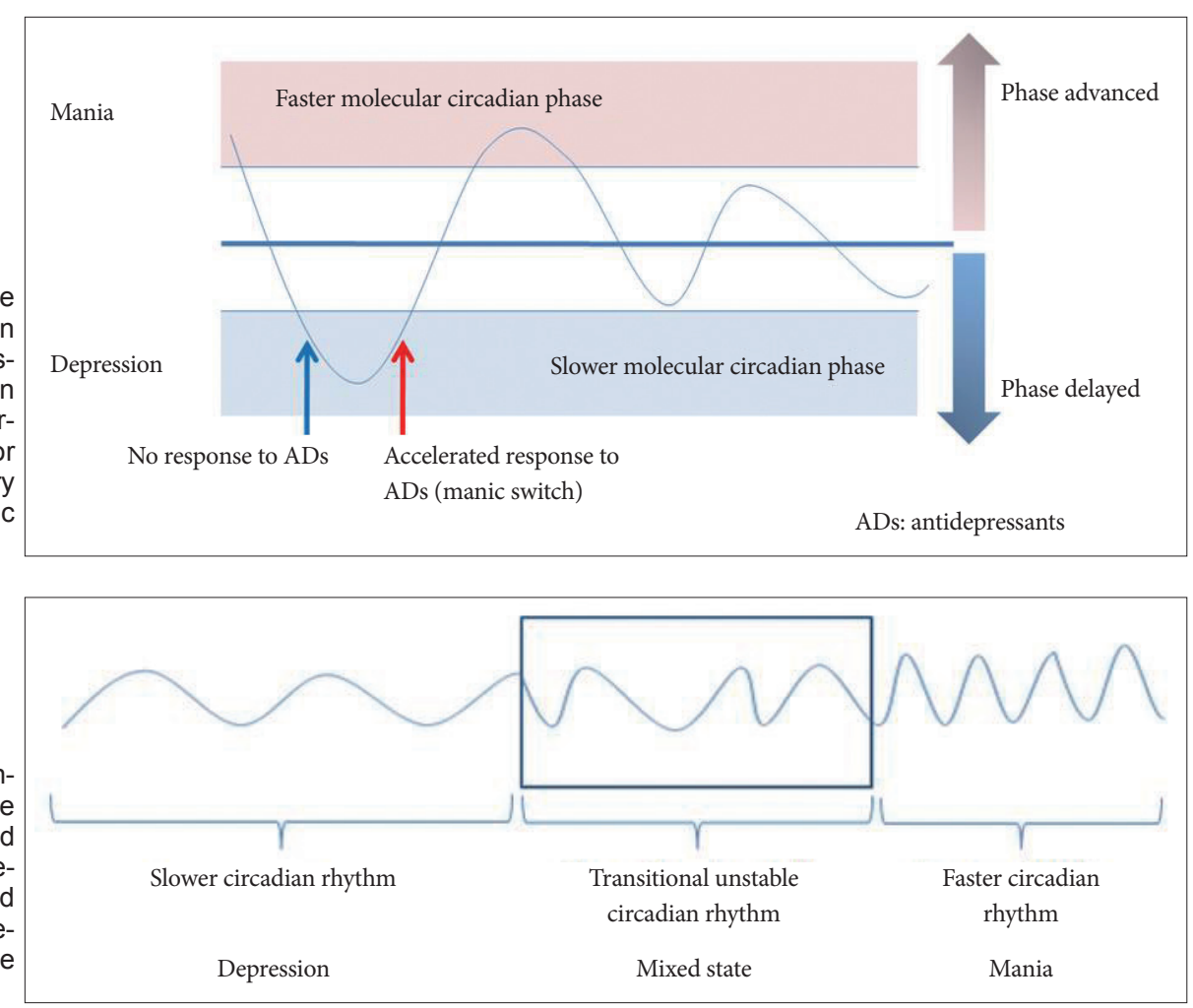

Figure 3. In case of mood shift happening without a substantial period of stable mood, i.e., during the transitional period between slower circadian rhythm of depression and faster one of mania, mood can be unstable and a combination of depressive and manic symptom at a same time. 
rience jet lag because of alterations to the body's circadian rhythms resulting from rapid long-distance airplane travel.

\section{CONCLUSIONS}

Circadian rhythm hypotheses are regarded as a promising explanation for BD development. Circadian rhythm instability, imposed on the dysfunction of HPA axis and monoamine system, may in turn increase individual susceptibility for switching from depression to mania/hypomania. Furthermore, different circadian phases may explain altering treatment response to antidepressants as well as the phenomena of mixed features. Recent data implicates the circadian system in the development of mood disorders. We suggest that dysregulation of the circadian system regulates the mechanisms of mixed features, antidepressant treatment resistance, and switching in mood disorders.

\section{Acknowledgments}

We wish to thank Dr. Daniel F. Kripke for his comments on the manuscript. This study was supported by the Korea Health 21 R\&D Project funded by the Ministry of Health \& Welfare, Republic of Korea (HI11C1901).

\section{REFERENCES}

1. Nestler EJ, Barrot M, DiLeone RJ, Eisch AJ, Gold SJ, Monteggia LM. Neurobiology of depression. Neuron 2002;34:13-25.

2. Murray CJ, Vos T, Lozano R, Naghavi M, Flaxman AD, Michaud C, et al. Disability-adjusted life years (DALYs) for 291 diseases and injuries in 21 regions, 1990-2010: a systematic analysis for the Global Burden of Disease Study 2010. Lancet 2013;380:2197-2223.

3. Akiskal HS, Bourge ois ML, Angst J, Post R, Moller H, Hirschfeld R. Re-evaluating the prevalence of and diagnostic composition within the broad clinical spectrum of bipolar disorders. J Affect Disord 2000; 59 (Suppl1):S5-S30.

4. Judd LL, Akiskal HS. The prevalence and disability of bipolar spectrum disorders in the US population: re-analysis of the ECA database taking into account subthreshold cases. J Affect Disord 2003;73:123131.

5. Bao AM, Meynen G, Swaab DF. The stress system in depression and neurodegeneration: focus on the human hypothalamus. Brain Res Rev 2008;57:531-553.

6. Capsi A, Sugden K, Moffitt TE, Taylor A, Craig IW, Harrington H, et al. Influence of life stress on depression: moderation by a polymorphism in the 5-HTT gene. Science 2003;301:386-389.

7. Lesch KP. Gene-environment interaction and the genetics of depression. J Psychiatry Neurosci 2004;29:174-184.

8. Linkowski P. Neuroendocrine profiles in mood disorders. Int J Neuropsychopharmacol 2003;6:191-197.

9. Goodwin FK, Jamison KR, Ghaemi SN. Manic-Depressive Illness: Bipolar Disorders and Recurrent Depression, 2nd Edition. New York: Oxford University Press; 2007.

10. Kripke DF, Mullaney DJ, Atkinson M, Wolf S. Circadian rhythm disorders in manic-depressives. Biol Psychiatry 1978;13:335-351.

11. Abe M, Herzog ED, Block GD. Lithium lengthens the circadian period of individual suprachiasmatic nucleus neurons. Neuroreport 2000;11: 3261-3264.

12. Linkowski P, Kerkhofs M, Van Onderbergen A, Hubain P, Copinschi G, LHermite-Baleriaux M, et al. The 24-hour profiles of cortisol, prolactin, and growth hormone secretion in mania. Arch Gen Psychiatry
1994;51:616-624.

13. Bunney BG, Bunney WE. Mechanisms of rapid antidepressant effects of sleep deprivation therapy: clock genes and circadian rhythms. Biol Psychiatry 2013;73:1164-1171.

14. Ehlers CL, Frank E, Kupfer DJ. Social zeitgebers and biological rhythms. A unified approach to understanding the etiology of depression. Arch Gen Psychiatry 1988;45:948-952.

15. Frank E, Kupfer DJ, Thase ME, Mallinger AG, Swartz HA, Fagiolini $\mathrm{AM}$, et al. Two-year outcomes for interpersonal and social rhythm therapy in individuals with bipolar I disorder. Arch Gen Psychiatry 2005;62:996-1004.

16. Tuunainen A, Kripke DF, Endo T. Light therapy for non-seasonal depression. Cochrane Database Syst Rev 2004;2:CD004050.

17. Sit D, Wisner KL, Hanusa BH, Stull S, Terman M. Light therapy for bipolar disorder: a case series in women. Bipolar Disord 2007;9:918-927.

18. McClung CA. How Might Circadian Rhythms Control Mood? Let Me Count the Ways. Biol Psychiatry 2013;74:242-249.

19. McCarthy MJ, Welsh DK. Cellular circadian clocks in mood disorders. J Biol Rhythms 2012;27:339-352.

20. Gunnar M, Quevedo K. The neurobiology of stress and development. Annu Rev Psychol 2007;58:145-173.

21. Sanchez MM. The impact of early adverse care on HPA axis development: Nonhuman primate models. Horm Behav 2006;50:623-631.

22. Chen J, Evans AN, Liu Y, Honda M, Saavedra JM, Aguilera G. Maternal deprivation in rats is associated with corticotrophin-releasing hormone (CRH) promoter hypomethylation and enhances $\mathrm{CRH}$ transcriptional responses to stress in adulthood. J Neuroendocrinol 2012; 24:1055-1064.

23. Murgatroyd C, Patchev AV, Wu Y, Micale V, Bockmuhl Y, Fischer D, et al. Dynamic DNA methylation programs persistent adverse effects of early-life stress. Nat Neurosci 2009;12:1559-1566.

24. Pariante CM, Miller AH. Glucocorticoid receptors in major depression: relevance to pathophysiology and treatment. Biol Psychiatry 2001; 49:391-404.

25. Juruena MF, Pariante CM, Papadopoulos AS, Poon L, Lightman S, Cleare AJ. Prednisolone suppression test in depression: prospective study of the role of HPA axis dysfunction in treatment resistance. $\mathrm{Br} J$ Psychiatry 2009;194:342-349.

26. Perlman WR, Webster MJ, Kleinman JE, Weickert CS. Reduced glucocorticoid and estrogen receptor alpha messenger ribonucleic acid levels in the amygdala of patients with major mental illness. Biol Psychiatry 2004;56:844-852.

27. Webster MJ, Knable MB, O'Grady J, Orthmann J, Weickert CS. Regional specificity of brain glucocorticoid receptor mRNA alterations in subjects with schizophrenia and mood disorders. Mol Psychiatry 2002; 7:985-994.

28. Howell MP, Muglia LJ. Effects of genetically altered brain glucocorticoid receptor action on behavior and adrenal axis regulation in mice. Front Neuroendocrinol 2006;27:275-284.

29. Ridder S, Chourbaji S, Hellweg R, Urani A, Zacher C, Schmid W, et al Mice with genetically altered glucocorticoid receptor expression show altered sensitivity for stress-induced depressive reactions. J Neurosci 2005;25:6243-6250.

30. Spijker AT, van Rossum EF, Hoencamp E, DeRijk RH, Haffmans J, Blom M, et al., Functional polymorphism of the glucocorticoid receptor gene associates with mania and hypomania in bipolar disorder. Bipolar Disord 2009;11:95-101.

31. Spijker AT, Giltay EJ, van Rossum EF, Manenschijn L, DeRijk RH, Haffmans J, et al., Glucocorticoid and mineralocorticoid receptor polymorphisms and clinical characteristics in bipolar disorder patients. Psychoneuroendocrinology 2011;36:1460-1469.

32. Szczepankiewicz A, Leszczyńska-Rodziewicz A, Pawlak J, RajewskaRager A, Dmitrzak-Weglarz M, Wilkosc M, et al., Glucocorticoid receptor polymorphism is associated with major depression and predominance of depression in the course of bipolar disorder. J Affect 
Disord 2011;134:138-144.

33. Schildkraut JJ. The catecholamine hypothesis of affective disorders: a review of supporting evidence. Am J Psychiatry 1965;122:509-522.

34. Matussek N. Biochemistry of depression. J Neural Transm 1972;33: 223-234.

35. Coppen A. The biochemistry of affective disorders. Br J Psychiatry 1967;113:1237-1264.

36. Lacasse JR, Leo J. Serotonin and depression: a disconnect between the advertisements and the Scientific literature. PLoS Med 2005;2:e392.

37. Holsboer F. The corticosteroid receptor hypothesis of depression. Neuropsychopharmacology 2000;23:477-501.

38. Juruena MF, Cleare AJ, Pariante CM. The hypothalamic pituitary adrenal axis, glucocorticoid receptor function and relevance to depression. Revista Brasileira de Psiquiatria 2004;26:189-201.

39. Klein M. Mourning and its relation to manic-depressive states. Int J Psychoanal 1940;21:125-153.

40. Paranjpe DA, Sharma VK. Evolution of temporal order in living organisms. J Circadian Rhythms 2005;3:7.

41. Wever RA. Characteristics of circadian rhythms in human functions. J Neural Transm 1986;Suppl 21:323-373.

42. Moore RY, Eichler VB. Loss of a circadian adrenal corticosterone rhythm following suprachiasmatic lesions in the rat. Brain Res 1972;42: 201-206.

43. Ralph MR, Foster RG, Davis FC, Menaker M. Transplanted suprachiasmatic nucleus determines circadian period. Science 1990;247:975978.

44. Silver R, LeSauter J, Tresco PA, Lehman MN. A diffusible coupling signal from the transplanted suprachiasmatic nucleus controlling circadian locomotor rhythms. Nature 1996;382:810-813.

45. Son GH, Chung S, Kim K. The adrenal peripheral clock: glucocorticoid and the circadian timing system. Front Neuroendocrinol 2011;32: 451-465.

46. Mansour HA, Monk TH, Nimgaonkar VL. Circadian genes and bipolar disorder. Ann Med 2005;37:196-205.

47. Welsh DK, Logothetis DE, Meister M, Reppert SM. Individual neurons dissociated from rat suprachiasmatic nucleus express independently phased circadian firing rhythms. Neuron 1995;14:697-706.

48. Czeisler CA, Klerman EB. Circadian and sleep-dependent regulation of hormone release in humans. Recent Prog Horm Res 1999;54:97113.

49. Scheer FA, Hu K, Evoniuk H, Kelly EE, Malhotra A, Hilton MF, Shea SA. Impact of the human circadian system, exercise, and their interaction on cardiovascular function. Proc Natl Acad Sci USA 2010;107: 20541-20546.

50. Balsalobre A, Brown SA, Marcacci L, Tronche F, Kellendonk C, Reichardt HM, et al. Resetting of circadian time in peripheral tissues by glucocorticoid signaling. Science 2000;289:2344-2348.

51. Sarai K, Kayano M. The level and diurnal rhythm of serum serotonin in manic-depressive patients. Folia Psychiatr Neurol Jpn 1968;22:271281.

52. Lee HJ, Kim L, Joe SH, Suh KY. Effects of season and climate on the first manic episode of bipolar affective disorder in Korea. Psychiatry Res 2002;113:151-159.

53. Lee HJ, Woo HG, Greenwood TA, Kripke DF, Kelsoe JR. A genomewide association study of seasonal pattern mania identifies NF1A as a possible susceptibility gene for bipolar disorder. J Affect Disord 2013; 145:200-207.

54. Boivin DB. Influence of sleep-wake and circadian rhythm disturbances in psychiatric disorders. J Psychiatry Neurosci 2000;25:446-458.

55. Lee HJ, Rex KM, Nievergelt CM, Kelsoe JR, Kripke DF. Delayed sleep phase syndrome is related to seasonal affective disorder. J Affect Disord 2011;133:573-579.

56. Wood J, Birmaher B, Axelson D, Ehmann M, Kalas C, Monk K, et al. Replicable differences in preferred circadian phase between bipolar disorder patients and control individuals. Psychiatry Res 2009;166:
201-209.

57. McCarthy MJ, Nievergelt CM, Shekhtman T, Kripke DF, Welsh DK, Kelsoe JR. Functional genetic variation in the Rev-Erba pathway and lithium response in the treatment of bipolar disorder. Genes Brain Behav 2011;10:852-861.

58. Dallaspezia S, Lorenzi C, Pirovano A, Colombo C, Smeraldi E, Benedetti F. Circadian clock gene Per3 variants influence the postpartum onset of bipolar disorder. Eur Psychiatry 2011;26:138-140.

59. Severino G, Manchia M, Contu P, Squassina A, Lampus S, Ardau R, et al. Association study in a Sardinian sample between bipolar disorder and the nuclear receptor REV-ERB alpha gene, a critical component of the circadian clock system. Bipolar Disord 2009;11:215-220.

60. Nievergelt CM, Kripke DF, Barrett TB, Burg E, Remick RA, Sadovnick $\mathrm{AD}$, et al. Suggestive evidence for association of the circadian genes PERIOD3 and ARNTL with bipolar disorder. Am J Med Genet B Neuropsychiatr Genet 2006;141B:234-241.

61. Benedetti F, Serretti A, Colombo C, Barbini B, Lorenzi C, Campori E, Smeraldi E. Influence of CLOCK gene polymorphism on circadian mood fluctuation and illness recurrence in bipolar depression. Am J Med Genet B Neuropsychiatr Genet 2003;123B:23-26.

62. Benedetti F, Bernasconi A, Lorenzi C, Pontiggia A, Serretti A, Colombo C, Smeraldi E. A single nucleotide polymorphism in glycogen synthase kinase 3-beta promoter gene influences onset of illness in patients affected by bipolar disorder. Neurosci Lett 2004;355:37-40.

63. Kripke DF, Nievergelt CM, Joo E, Shekhtman T, Kelsoe JR. Circadian polymorphisms associated with affective disorders. J Circadian Rhythms 2009;7:2.

64. Scott LJ, Muglia P, Kong XQ, Guan W, Flickinger M, Upmanyu R, et al. Genome-wide association and meta-analysis of bipolar disorder in individuals of European ancestry. Proc Natl Acad Sci USA 2009;106: 7501-7506.

65. Ferreira MA, O’Donovan MC, Meng YA, Jones IR, Ruderfer DM, Jones $\mathrm{L}$, et al. Collaborative genome-wide association analysis supports a role for ANK3 and CACNA1C in bipolar disorder. Nat Genet 2008; 40:1056-1058.

66. Sklar P, Ripke S, Scott LJ, Andreassen OA, Cichon S, Craddock N, et al. Large-scale genome-wide association analysis of bipolar disorder identifies a new susceptibility locus near ODZ4. Nat Genet 2011;43: 977-983.

67. McCarthy MJ, Nievergelt CM, Kelsoe JR, Welsh DK. A survey of genomic studies supports association of circadian clock genes with bipolar disorder spectrum illnesses and lithium response. PLoS One 2012;7: e32091.

68. Patel SD, Le Niculescu H, Koller DL, Green SD, Lahiri DK, McMahon FJ, et al. Coming to grips with complex disorders: genetic risk prediction in bipolar disorder using panels of genes identified through convergent functional genomics. Am J Med Genet B Neuropsychiatr Genet 2010;153B:850-877.

69. Easton A, Arbuzova J, Turek FW. The circadian Clock mutation increases exploratory activity and escape-seeking behavior. Genes Brain Behav 2003;2:11-19.

70. Harada Y, Sakai M, Kurabayashi N, Hirota T, Fukada Y. Ser-557-phosphorylated mCRY2 is degraded upon synergistic phosphorylation by glycogen synthase kinase-3 beta. J Biol Chem 2005;280:31714-31721.

71. Gould TD, Manji HK. Glycogen synthase kinase-3: a putative molecular target for lithium mimetic drugs. Neuropsychopharmacology 2005; 30:1223-1237.

72. Klemfuss H. Rhythms and pharmacology of lithium. Pharmacol Ther 1992;56:53-78.

73. Basturk M, Karaaslan F, Esel E, Sofuoglu S, Tutus A, Yabanoglu I. Effects of short and long-term lithium treatment on serum prolactin levels in patients with bipolar affective disorder. Prog Neuropsychopharmacol Biol Psychiatry 2001;25:315-322.

74. Campbell SS, Gillin JC, Kripke DF, Janowsky DS, Risch SC. Lithium delays circadian phase of temperature and REM sleep in a bipolar de- 
pressive: a case report. Psychiatry Res 1989;27:23-29.

75. Hitzemann R, Kao L, Hirschowitz J, Garver D, Gruenstein E. Lithium transport in human fibroblasts: relationship to RBC lithium transport and psychiatric diagnoses. Psychiatry Res 1988;24:337-344.

76. Mellerup ET, Lauritsen B, Dam H, Rafaelson OJ. Lithium effects on diurnal rhythm of calcium, magnesium, and phosphate metabolism in manic-melancholic disorder. Acta Psychiatr Scand 1976;53:360-370.

77. Ogden CA, Rich ME, Schork NJ, Paulus MP, Geyer MA, Lohr JB, et al. Candidate genes, pathways and mechanisms for bipolar (manic-depressive) and related disorders: an expanded convergent functional genomics approach. Mol Psychiatry 2004;9:1007-1029.

78. Manev H, Uz T. Clock genes: influencing and being influenced by psychoactive drugs. Trends Pharmacol Sci 2006;27:186-189.

79. Lewy AJ, Wehr TA, Goodwin FK, Newsome DA, Rosenthal NE. Manic-depressive patients may be supersensitive to light. Lancet 1981;1:383384.

80. Benedetti F, Colombo C, Barbini B, Campori E, Smeraldi E. Morning sunlight reduces length of hospitalization in bipolar depression. J Affect Disord 2001;62:221-223.

81. Wu JC, Kelsoe JR, Schachat C, Bunney BG, DeModena A, Golshan S, et al. Rapid and sustained antidepressant response with sleep deprivation and chronotherapy in bipolar disorder. Biol Psychiatry 2009;66: 298-301.

82. Deltito JA, Moline M, Pollak C, Martin LY, Maremmani I. Effects of phototherapy on non-seasonal unipolar and bipolar depressive spectrum disorders. J Affective Disord 1991;23:231-237.

83. Chan PK, Lam RW, Perry KF. Mania precipitated by light therapy for patients with SAD. J Clin Psychiatry 1994;55:454.

84. Kripke DF. Timing of phototherapy and occurrence of mania. Biol Psychiatry 1991;29:1156-1157.

85. Barbini B, Benedetti F, Colombo C, Dotoli D, Bernasconi A, CigalaFulgosi M, et al. Dark therapy for mania: a pilot study. Bipolar Disord 2005;7:98-101.

86. Bunney WE, Bunney BG. Molecular clock genes in man and lower animals: possible implications for circadian abnormalities in depression. Neuropsychopharmacology 2000;22:335-345.

87. Hampp G, Ripperger JA, Houben T, Schmutz I, Blex C, Perreau-Lenz $\mathrm{S}$, et al. Regulation of monoamine oxidase A by circadian-clock component implies clock influence on mood. Current Biology 2008;18:678683.

88. Hampp G, Albrecht U. The circadian clock and mood-related behavior. Commun Integr Biol 2008;1:1-3.

89. Spencer S, Falcon E, Kumar J, Krishnan V, Mukherjee S, Birnbaum SG, McClung CA. Circadian genes Period 1 and Period 2 in the nucleus accumbens regulate anxiety-related behavior. Eur J Neurosci 2013; 37:242-250.

90. McClung CA, Sidiropoulou K, Vitaterna M, Takahashi JS, White FJ, Cooper DC, Nestler EJ. Regulation of dopaminergic transmission and cocaine reward by the Clock gene. Proc Natl Acad Sci USA 2005;102: 9377-9381.

91. Roybal K, Theobold D, Graham A, DiNieri JA, Russo SJ, Krishnan V, et al. Mania-like behavior induced by disruption of CLOCK. Proc Natl Acad Sci USA 2007;104:6406-6411.

92. Coque L, Mukherjee S, Cao JL, Spencer S, Marvin M, Falcon E, et al.
Specific role of VTA dopamine neuronal firing rates and morphology in the reversal of anxiety-related, but not depressionrelated behavior in the ClockDelta19 mouse model of mania. Neuropsychopharmacology 2011;36:1478-1488.

93. Lish JD, Dime-Meenan S, Whybrow PC, Price RA, Hirschfeld RM. The National Depressive and Manic-depressive Association (DMDA) survey of bipolar members. J Affect Disord 1994;31:281-294.

94. Papadimitriou GN, Calabrese JR Dikeos DG, Christodoulou GN. Rapid cycling in bipolar disorder: biology and pathogenesis. Int J Neuropsychopharmacol 2005;8:281-292.

95. Bunney WE, Jr, Murphy DL, Goodwin FK, Borge GF. The switch process from depression to mania: relationship to drugs, which alter brain amines. Lancet 1970;1:1022-1027.

96. Bunney WE, Jr, Goodwin FK, Murphy DL, House KM, Gordon EK. The 'switch process' in manic-depressive illness. II. Relationship to catecholamines, REM sleep, and drugs. Arch Gen Psychiatry 1972;27:304309.

97. Wehr TA, Goodwin FK. Rapid cycling in manic-depressives induced by tricyclic antidepressants. Arch Gen Psychiatry 1979;36:555-559.

98. Wehr TA, Goodwin FK. Can antidepressants cause mania and worsen the course of affective illness? Am J Psychiatry 1987;144:1403-1411.

99. Wehr TA, Sack DA, Rosenthal NE, Cowdry RW. Rapid cycling affective disorder: contributing factors and treatment responses in $51 \mathrm{pa}-$ tients. Am J Psychiatry 1988;145:179-184.

100. Li CT, Bai YM, Huang YL, Chen YS, Chen TJ, Cheng JY, Su TP. Association between antidepressant resistance in unipolar depression and subsequent bipolar disorder: cohort study. Br J Psychiatry 2012;200: 45-51.

101. Calabrese JR, Rapport DJ, Kimmel SE, Shelton MD. Controlled trials in bipolar I depression: focus on switch rates and efficacy. Eur Neuropsychopharmacol 1999;9(Suppl 4):S109-S112.

102. Hudson JI, Lipinski JF, Frankenburg FR, Grochocinski VJ, Kupfer DJ. Electroencephalographic sleep in mania. Arch Gen Psychiatry 1988; 45:267-273.

103. Hudson JI, Lipinski JF, Keck PE Jr, Aizley HG, Lukas SE, Rothschild AJ, et al. Polysomnographic characteristics of young manic patients: comparison with unipolar depressed patients and normal control subjects. Arch Gen Psychiatry 1992;49:378-383.

104. Lewy AJ, Lefler BJ, Emens JS, Bauer VK. The circadian basis of winter depression. Proc Natl Acad Sci USA 2006;103:7414-7419.

105. Sprouse J, Braselton J, Reynolds L. Fluoxetine modulates the circadian biological clock via phase advances of suprachiasmatic nucleus neuronal firing. Biol Psychiatry 2006;60:896-899.

106. Kraepelin E. Manic-Depressive Illness and Paranoia. Edinburgh: E \& S Livingstone; 1921.

107. Kotin J, Goodwin FK. Depression during mania: clinical observations and theoretical implications. Am J Psychiatry 1972;129:679-686.

108. Turvey CL, Coryell WH, Solomon DA, Leon AC, Endicott J, Keller MB, Akiskal H. Long-term prognosis of bipolar I disorder. Acta Psychiatr Scand 1999;99:110-119.

109. Mukherjee S, Coque L, Cao JL, Kumar J, Chakravarty S, Asaithamby A, et al. Knockdown of Clock in the ventral tegmental area through RNA interference results in a mixed state of mania and depression-like behavior. Biol Psychiatry 2010;68:503-511. 